\title{
Profile of Children Born to HIV-Positive Mothers Followed-up in the Borgou/ Alibori Regional University Teaching Hospital from 2005 to 2015
}

\author{
Agossou J ${ }^{1^{*}}$, Noudamadjo A ${ }^{1}$, Adédémy JD ${ }^{1}$, Agbeille Mohamed F ${ }^{1}$, Kpanidja MG ${ }^{1}$, Doha F ${ }^{1}$, Sagbo GG ${ }^{2}$, \\ Lalya $\mathrm{HF}^{2}$, Ahodégnon $\mathrm{R}^{1}$, Adéothy-Koumakpaï $\mathrm{S}^{2}$ \\ ${ }^{1}$ Mother and Child Department, University of Parakou and Borgou/Alibori Regional University Hospital, BP 02 Parakou, Benin; \\ ${ }^{2}$ Mother and Child Department, Faculty of Health Sciences, University of Abomey-Calavi, BP 188 Cotonou, Benin
}

\begin{abstract}
Introduction: Prevention of Mother-to-Child Transmission (PMTCT) of HIV is the best strategy for fighting pediatric HIV in developing countries. This study's main objective was to describe the outcome of children born to HIV positive mothers, attended and followed up through the PMTCT program in the Borgou/Alibori Regional University Teaching Hospital (CHUD-Borgou/Alibori) from 2005 to 2015. Secondly, it aimed to identify factors associated with mother-to-child transmission of HIV at 18 months of age.

Patients and Methods: This research work is a cross-sectional, retrospective, descriptive and analytical study of a cohort of children born to HIV-infected mothers and followed up in the pediatric ward of the Borgou/Alibori Regional University Teaching Hospital. It was conducted from May to December 2016 on the basis of data retrieval from medical records and registers.

Results: Total of 1234 children was included in the study. Exclusive breastfeeding was the main source of nutrition for $91.6 \%$ of children. Antiretroviral prophylaxis was received by $82.7 \%$ of children at birth. $49.4 \%$ of the 1234 children (610/1234) were followed up till 18 months of age; $36.5 \%$ were lost to follow-up and $4.1 \%$ died. Overall rate of mother-to-child HIV transmission was 5.6\% (34/610), of which 1.8\% (9/509) was among children who received antiretroviral prophylaxis at birth. Two predictive factors for mother-to-child transmission of HIV were found: absence of clean and safe childbirth and lack of antiretroviral prophylaxis in children at birth.

Conclusion: Improved antenatal care quality and efficient childbirth management with early mothers' adherence to pediatric follow-up may help reduce vertical HIV transmission in this study environment.
\end{abstract}

Keywords: PMTCT; Children; HIV; Benin

\section{INTRODUCTION}

Human immunodeficiency virus (HIV) infection is still globally a major public health problem. Africa bears the heaviest burden in the world since it hosts 23.5 million people living with HIV (PLHIV) [1]. In 2015, 6.5 million PLHIV were recorded in West and Central Africa, including nearly $60 \%$ of women. Among children, 66,000 out of 150,000 new pediatric HIV infections across the world occurred in these areas during the same year [2]. Therefore, children are not spared from the AIDS pandemics since most of them are encountered in developing countries
$[3,4]$. In response to that situation of great concern, many strategies such as Prevention of Mother-to-Child Transmission of HIV have been developed over the years in order to reduce the risk of mother-to-child transmission of HIV [5]. Since 2005, the Pediatric Unit of CHUD-Borgou/Alibori has become a site providing care for HIV infected and exposed children. What is the outcome or result of that follow-up? The main objective of this study was to describe the outcome of children born to HIVpositive mothers followed up in the Borgou/Alibori Regional University Teaching Hospital (CHUD-B/A) from 2005 to 2015.

*Correspondence to: Joseph Agossou, Mother and Child Department, University of Parakou and Borgou/Alibori Regional University Hospital, BP 02 Parakou, Benin, Tel: 229 97693677; Email: agossoujoseph@gmail.com

Received: September 09, 2019; Accepted: October 07, 2019; Published: October 14, 2019

Citation: Agossou J, Noudamadjo A, Adédémy JD, Mohamed AF, Kpanidja MG, Doha F, et al. (2019) Profile of Children Born to HIV-Positive Mothers Followed-up in the Borgou/Alibori Regional University Teaching Hospital from 2005 to 2015. Clinics Mother Child Health. 16:335. DOI: $10.35248 / 2090-7214.19 .16 .335$

Copyright: (C2019 Agossou J, et al. This is an open-access article distributed under the terms of the Creative Commons Attribution License, which permits unrestricted use, distribution, and reproduction in any medium, provided the original author and source are credited. 
Secondly, it consisted in identifying the factors associated with mother-to-child transmission of HIV at 18 months of age.

\section{PATIENTS AND METHODS}

This was a descriptive and analytical retrospective cross-sectional study that took place at CHUD-Borgou / Alibori in Parakou from 1 May to 31 December 2016. Data collection involved all the cases registered from January 1, 2005, to December 31, 2015 i.e. during an 11-year period. The study population consisted of all children born to HIV-positive mothers and followed-up in the Pediatric Unit of CHUD-Borgou/Alibori during the 11 years. It was a comprehensive census systematically including all children born to HIV-positive mothers who had been seen at least once in PMTCT. On each medical consultation, the nutritional status of followed-up children was systematically assessed on the basis of weight-for-height z-score and mid-upperarm circumference (MUAC). The PMTCT Guidelines followed has undergone a continuous evolution in accordance with the WHO guidelines and was updated by The National AIDS Control Program (PNLS) between 2005 and 2013. For instance, during the first Guidelines, all the parturients who gave birth in public maternity received Single-dose Nevirapine (because Single-dose Nevirapine was the only Guidelines available) and were provided particular care intended for HIV-positive woman in the delivery room in accordance with the WHO recommendations (clean and safe birth). After that period in which Single-dose Nevirapine was administered, another period followed the first one during which two Guidelines coexisted depending on childbirth setting. Nevirapine Guidelines were administered in peripheral maternities. It consists of Single-dose Nevirapine given to the pregnant woman at the beginning of labor, and Single-dose Nevirapine given to the newborn within the $72 \mathrm{~h}$ following birth. When childbirth happens in the maternity of CHUD-Borgou/Alibori, the Guidelines used was Triple antiretroviral prophylaxis based on combination of Zidovudine (AZT), Lamivudine (3TC) and Nevirapine (NVP) from the 28th week of amenorrhea up to the end of exclusive breastfeeding i.e. 6 months for mothers who chose to exclusively breastfeed their children. As regards those who chose artificial feeding, triple prophylaxis stopped for each mother at childbirth if she was not eligible for antiretroviral drugs program (absence of immunosuppression, CD4 cell count $>500 / \mathrm{mm}^{3}$ ). Concerning the newborn whose mother chose exclusive breastfeeding, triple prophylaxis included administration of Single-dose Nevirapine at birth, combined with administration of Zidovudine and Lamivudine for 21 days. From 2012, the PMTCT Guidelines applied is one of option $\mathrm{B}^{+}$; it consists in giving three antiretroviral drugs as soon as HIV-positive status is confirmed in a pregnant woman. In addition, it also consists of continuing throughout life triple antiretroviral drugs therapy in the HIV-positive pregnant woman and antiretroviral prophylaxis made of Nevirapine or Zidovudine in child during the first six weeks of life, and safe breastfeeding [6]. The first-line regimen adopted was: Tenofovir (TDF)+3TC+EFV in case of HIV1 infection. In case of TDF shortage and absence of anemia, TDF is replaced by Zidovudine. From 2010, Polymerase Chain Reaction (PCR) in the child was introduced in PMTCT monitoring. For instance, 6 weeks after birth, child blood was collected into blotting paper for PCR1. Another blood sample was collected for PCR2 six to eight weeks after early weaning occurred at 6 months of age. HIV serology was performed at 18 months of age.

The tools used for data collection were medical consultation registers, individual health records of identified children, PMTCT registers, serology registers, and PCR registers. The dependent variable was virology status and/or HIV serological status at 18 months. The independent variables investigated were socio-demographic, clinical, biological, therapeutic, outcome and variables related to children's feeding pattern. The software Epi-Info 7.2 was used to enter data. The measures of central tendency of quantitative variables were described through the computation of mean values and their standard deviation. As regards qualitative variables, proportions were determined. Proportions and ratios were compared using Khi2 test, and difference was considered as significant if p-value < 0.05. The predictive factors for transmission of HIV infection were identified through multivariate analysis. Binary logistic regression was the model used.

\section{RESULTS}

\section{Chronological progression of cases of children born to HIV-positive mothers followed up in the Pediatric unit from 2005 to 2015}

During the study period, 56,963 children were attended for medical consultation, including 1234 children born to HIVpositive mothers, i.e. a hospital admission rate of $2.2 \%$. Figure 1 shows the chronological progression of admissions of children born to HIV-positive mothers followed-up in the Pediatric unit of CHUD-Borgou/Alibori from 2005 to 2015.

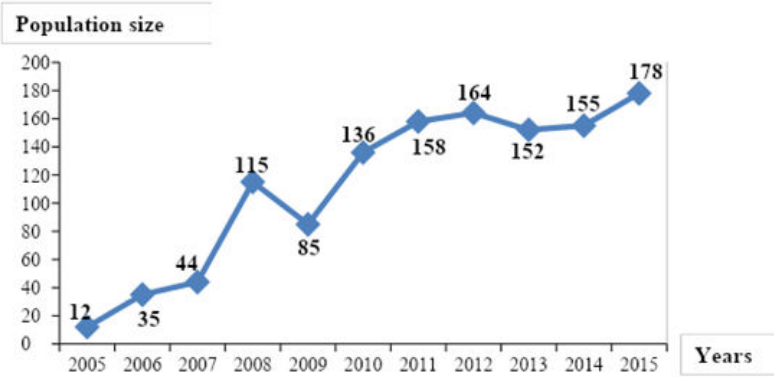

Figure 1: Chronological progression of admissions of children born to HIV-positive mothers followed up in the Pediatric unit of CHUDBorgou/Alibori from 2005 to $2015(\mathrm{~N}=1234)$.

\section{Socio-demographic, clinical, biological, therapeutic features and dietary patterns of children followed-up}

Among the 1234 children followed-up, 53.2\% (656/1234) were male and $46.8 \%$ female i.e. a sex ratio of 1.1 . The mean age for mothers was $28.27 \pm 5.2$ years and $80.5 \%$ of them were less than 35 years. They belonged to disadvantaged socio-professional categories in $81.1 \%(1001 / 1234)$ of cases. Spouses were informed of the serological status of their consorts in $40.5 \%$ of cases (500/1234). Concerning parents' vital status, $3.8 \%$ of children followed-up were orphans who lost at least one parent. 
The time limit for first medical visit after children's birth was less than 3 days in $26.1 \%$ of cases (322/1224), between 3 and 7 days in $22.5 \%(278 / 1234)$, between 8 and 30 days in $18.6 \%$ (230/1234), and more than 30 days in 32.7\% (404/1234). During the study period, 1020 children had benefitted from antiretroviral prophylaxis i.e. $82.7 \%$ and 1077 (87.3\%) had benefitted from cotrimoxazole prophylaxis. During the monitoring, the most common diseases were acute respiratory infections in $46.8 \%(283 / 605)$ of cases, then digestive infections in $23.8 \%(144 / 605)$ of cases and finally malaria in $15.4 \%(93 / 605)$ of cases. Among those children, 782 benefitted from PCR; 37 of them proved to be positive (5.5\%) and 633 were negative (94.5\%). Among the 285 children who were administered PCR2, 11 were positive (3.9\%). Among the latter 6 had been previously positive (54.5\%). Among the 1005 children who were at least 18 months at the time of the study, 610 (60.7\%) performed HIV serology. Among these 610 children, 34 were HIV-positive (5.6\%).,Among those 34 HIV-positive children, as regards PCR1, 14 had previously been positive, 4 had been tested negative and 16 had not previously benefitted from PCR1. Concerning dietary pattern, 1130 (93.5\%) were on exclusive breastfeeding, $52(04.3 \%)$ on artificial feeding and 26 $(02.2 \%)$ on mixed feeding. The weaning period was specified in 940 of them, including 175 at 4 months of age (18.6\%), 363 at 6 months (38.6\%) and 402 between 6 and 12 months (42.8\%). The assessment of nutritional status at 18 months showed that $4.7 \%$ of children followed-up suffered from severe acute malnutrition, $12.8 \%$ suffered from moderate acute malnutrition and $82.5 \%$ enjoyed a good nutritional status.

\section{Outcome of children followed-up until 18 months}

Among the 1234 children included in the study, $49.4 \%$ (610/1234) were followed-up till 18 months of age, $36.5 \%$ (451/1234) were lost to follow-up, 8.3\% (102/1234) were being followed up, 4.1\% (51/1234) died and 1.6\% (20/1234) was referred to other health centers. Among the 610 children who benefitted from HIV serology at 18 months, 576 (94.4\%) were HIV-negative. The overall rate of mother-to-child HIV transmission was $5.6 \%(34 / 610)$, including $1.8 \%(9 / 509)$ in children who benefitted from antiretroviral prophylaxis at birth.

\section{Relationship between socio-demographic features, characteristics related to follow-up of children born to HIV-positive mothers and transmission of HIV infection}

In this study, maternal orphan status, absence of antiretroviral prophylaxis at birth, lack of safe breastfeeding and delay in the start of co-trimoxazole (CTX) prophylaxis were statistically associated with the transmission of HIV infection, respectively with $p=0.0400 ; p=0.0010 ; p=0.0010 ; p=0.0440$. Table 1 shows the relationship existing between socio-demographic features, characteristics related to the monitoring of children born to HIV-positive mothers and transmission of HIV infection.

Table 1: Relationship between socio-demographic features, characteristics related to the monitoring of children born to HIV-positive mothers and transmission of HIV infection in CHUD-Borgou/Alibori from 2005 to 2015.

Transmission of HIV infection

\begin{tabular}{|c|c|c|c|c|c|c|c|c|}
\hline & & & Yes & & No & & & \\
\hline & Total & $\mathbf{n}$ & $\%$ & $\mathrm{n}$ & $\%$ & OR & $95 \% \mathrm{CI}$ & $\mathrm{p}$ \\
\hline Sex of the child $(N=610)$ & & & & & & & & 0.2453 \\
\hline Male & 328 & 15 & 4.6 & 313 & 95.4 & 1 & & \\
\hline Female & 282 & 19 & 6.7 & 263 & 93.3 & 1.5 & {$[0.7-3,0]$} & \\
\hline Maternal orphan status $(\mathrm{N}=610)$ & & & & & & & & 0.0400 \\
\hline Yes & 604 & 32 & 5.3 & 572 & 94.7 & 8.9 & {$[1.6-50.6]$} & \\
\hline No & 6 & 2 & 33.3 & 4 & 66.7 & 1 & & \\
\hline Antiretroviral prophylaxis at birth $(\mathrm{N}=596)$ & & & & & & & 0.001 & \\
\hline Yes & 543 & 19 & 3.5 & 524 & 96.5 & 1 & & \\
\hline No & 53 & 14 & 26.4 & 39 & 73.6 & 9.9 & {$[4.6-21.2]$} & \\
\hline Clean and safe childbirth $(\mathrm{N}=571)$ & & & & & & & 0.0001 & \\
\hline Yes & 491 & 479 & 97.6 & 12 & 2.4 & 1 & & \\
\hline
\end{tabular}




\begin{tabular}{|c|c|c|c|c|c|c|c|}
\hline No & 80 & 61 & 76.3 & 19 & 23.8 & 12.4 & [5.8-26.9] \\
\hline Feeding pattern $(\mathrm{N}=610)$ & & & & & & & 0.119 \\
\hline EBF & 572 & 32 & 5.6 & 540 & 94.4 & 1 & \\
\hline Milk substitutes & 25 & 0 & 0 & 25 & 100 & - & - \\
\hline Mixed feeding & 13 & 2 & 15.4 & 11 & 84.6 & 3.1 & {$[0.6-14.4]$} \\
\hline Safe breastfeeding $(\mathrm{N}=565)$ & & & & & & & 0.0001 \\
\hline Yes & 516 & 19 & 3.7 & 497 & 96.3 & 1 & \\
\hline No & 49 & 13 & 26.5 & 36 & 73.5 & 9.4 & {$[4.3-20.6]$} \\
\hline $\begin{array}{l}\text { Delay in the start of co- } \\
(\mathrm{N}=598)\end{array}$ & & & & & & & 0.0440 \\
\hline Yes & 26 & 22 & 84.6 & 4 & 15.4 & 3.5 & [1.1-10.9] \\
\hline No & 572 & 544 & 95.1 & 28 & 4.9 & 1 & \\
\hline
\end{tabular}

\section{Predictive factors for transmission of HIV infection during the study}

In this study, the absence of clean and safe birth and lack of antiretroviral prophylaxis at birth were the predictive factors for transmission of HIV infection after multivariate analysis. Table 2 outlines the predictive factors for mother-to-child transmission of HIV infection.

Table 2: Predictive factors for vertical HIV transmission in CHUDBorgou/Alibori from 2005 to 2015.

\begin{tabular}{lll}
\hline & $\mathrm{p}$ & $\mathrm{RP} 95 \% \mathrm{IC}$ \\
\hline Maternal orphan status & 0.287 & 0.51 [0.15-1.76] \\
\hline Lack of Antiretroviral prophylaxis at birth & 0.0001 & $24.6[10.2-59.3]$ \\
\hline Absence of clean and safe childbirth & 0.0001 & $12.4[5.7-29.6]$ \\
\hline $\begin{array}{l}\text { Absence of safe breastfeeding } \\
\begin{array}{l}\text { Delay in the start of co-trimoxazole } \\
\text { prophylaxis }\end{array}\end{array}$ & 0.066 & 1.55 [0.35-8.27] \\
\hline
\end{tabular}

\section{DISCUSSION}

Chronological progression of cases of children born to HIV-positive mothers followed-up in the Pediatric unit from 2005 to 2015

The trend illustrated in Figure 1 shows a growing increase in the number of children born to HIV-positive mothers followed in the pediatric unit, rising from 12 cases in 2005 to 115 cases in 2008 and then from 164 cases in 2012 and ultimately to 178 cases in 2015. This increasing progression of cases of children followed-up within the framework of PMTCT may be due to the availability of the staff dedicated to that activity in the unit. It may particularly be due to the networking of public and private maternities of the district of Parakou and its suburban areas between 2007 and 2012. Despite the decentralization of PMTCT activities towards peripheral maternities from 2013, the pediatric unit continues to attend a significant number of cases of children born to HIV-positive mothers.

\section{Socio-demographic, clinical, biological, therapeutic characteristics and dietary pattern of children followed- up}

Forty-seven children were orphans of one parent i.e. a rate of $3.8 \%(47 / 1234)$. This state of things raises the issue of child custody as well as child follow-up and survival. In this study, children whose mother was dead were more at risk for vertical transmission than those who did not have that orphan status. The risk of being infected with a child whose mother is alive is multiplied by 8.8 than in a maternal orphan. This observation may be associated with clinical stage III or IV of the mother during or at the end of pregnancy.

Concerning age at first medical follow-up visit, only $26.1 \%$ of children were attended in first medical consultation before $72 \mathrm{~h}$ of life, which is the prescribed time limit in accordance with PMTCT standards applicable in Benin [6]. This low rate of children brought to first medical consultation represents a bottleneck in the implementation of PMTCT-related standards in Benin. In the local sociocultural context, parturient is always accompanied when she is admitted to give birth in health-care facilities. This tradition may not enable parturients to get to the pediatric unit on time, particularly because HIV/AIDS infection is and continues to be a taboo topic in our environment. There is an urgent need to institutionalize newborn systematic examination at all levels of the health pyramid of Benin during 
the first week of life as usually done in developed countries. So, infants born to HIV-positive mothers would benefit from early care in compliance with applicable standards. Concerning the first pediatric consultation within the framework of follow-up of children born to HIV-positive mothers, the risk of vertical HIV transmission is significantly associated with delay in the implementation of first follow-up consultation. This risk increases depending on age upon admission. For instance, the risk of being infected is multiplied by 1.1 in children who benefitted from medical consultation within 3 to 7 days, by 2.1 in those attended for follow-up consultation between 8 and 30 days, and by 10.8 in children examined after 30 days. This remark may be due to the fact that first consultation is a vital step in care provision for children born to an HIV-positive mother. This consultation is an opportunity for the child to benefit from antiretroviral prophylaxis if it was not done at the maternity before the $72 \mathrm{nd}$ hour of life. In principle, in accordance with the applicable guidelines, the choice of newborn feeding pattern is made before birth. And the mother is reminded of choice during the first follow-up consultation.

As regards morbid appearances encountered during the followup of HIV-exposed children during this study, the most common diseases were acute respiratory infections (46.8\%), digestive infections (23.8\%) and malaria (15.4\%). A study conducted in Togo in 2011 by Azoumah et al. on HIV-exposed children had noted $38.5 \%$ of cases of acute respiratory infections, $36.9 \%$ of malaria and $12.4 \%$ cases of oral thrush [7].

As regards biological monitoring, PCR 1 was performed in only $51.2 \%$ of cases and $5.5 \%$ tested positive. This low PCR1 rate was due on the one hand to the start of this activity only from 2010; on the other hand, it was due to various shortages of reagents, and also to dysfunctions of the automaton dedicated to that activity. That PCR1 positive status rate found out in this study i.e. $5.5 \%$ is comparable to the one reported in 2010 by Adédémy et al. [8] in the same hospital unit i.e. $6.4 \%$. The overall positive status rates found in two other studies, one in Benin in 2010 and another in Mali in 2013, were respectively $9.7 \%$ and $7.3 \%[9,10]$. In In in Johannesburg (South Africa), lower rates were obtained: $2.7 \%$ in 2010 and $1.1 \%$ in 2011, while 3.3\% between 2007 and 2010 in Lusaka (Zambia) and 4.6\% between 2009 and 2011 in Lilongwe (Malawi) [11,12]. The positive status of PCR1 performed at six weeks of life reflects early contamination of the child, either in utero or during childbirth.

In this study, $87.3 \%$ of children had received prophylactic treatment based on co-trimoxazole. This ratio of children on cotrimoxazole prophylaxis is lower than the one found out by Azoumah et al. in Togo in 2010 i.e. 95.7\% and higher than the one found by Gbogbo in the National University Teaching Hospital (CNHU) of Cotonou in 2010 (79.8\%) [7,13]. In accordance with the applicable PMTCT guidelines, all children born to HIV-positive mothers should receive co-trimoxazole prophylaxis from six weeks of life until the time of certainty of non-contamination of the child [6]. Delay in the start-up of cotrimoxazole prophylaxis among children was significantly associated with child contamination at 18 months $(p<0.001)$. The risk of being contaminated is multiplied by 8 in children when co-trimoxazole prophylaxis has not started on time. Concerning the effectiveness of antiretroviral prophylaxis in children, more than eight out of ten children $(82.7 \%)$ had benefitted from antiretroviral prophylaxis at birth. This rate is close to those found out by Ahoua et al. in Uganda in 2009 (85.8\%), Gbogbo et al. in 2011 in Cotonou (92.7\%) and Ouédraogo et al. in 2015 in Burkina Faso (90.4\%) [13-15]. The absence of antiretroviral prophylaxis at birth is significantly associated with child contamination $(p=0.001)$. For instance, the risk of being infected is multiplied by 18 in children who did not receive antiretroviral prophylaxis at birth compared to those who received it. This study's findings confirmed those found out by two authors which demonstrate all the benefits of antiretroviral prophylaxis at birth in HIV-exposed children $[14,16]$. These findings suggest that any pregnant woman must get tested systematically so that her child may be provided antiretroviral prophylaxis at birth.

It is admitted that the dietary pattern of children born to HIVpositive mothers may facilitate mother to child transmission of virus up to potentially more than $15 \%$. Actually, avoidance of breastfeeding in newborns and infants born to HIV-positive mothers in developed countries has helped reduce significantly mother-to-child HIV transmission rate. However, in the local context of country with limited resources characterized by poor drinking water supply and more than $80 \%$ of illiterate mothers, the use of milk substitutes may represent a hazard for the survival of those children. Exclusive breastfeeding secured by ARV until six months of age facilitates the maintenance of gastro-intestinal barrier integrity in the child. Therefore, it is a beneficial alternative for exposed children in such a context. Besides, American authors have demonstrated the presence of neutralizing protein (Tenascin-C) in breast milk; such a protein is likely to reduce HIV activity [17]. In this study, exclusive breastfeeding until six months was the main feeding pattern of exposed children in $91.6 \%$ of cases included in our cohort, versus $4.2 \%$ of children fed with milk substitutes. This high rate of exclusive breastfeeding pointed out in the study may be due to the fact that in the local sociocultural context, breastfeeding is the usual feeding pattern of newborns and infants. This type of feeding combined with antiretroviral therapy (ART) in the mother is recommended by the National AIDS Control Program in Benin (Option $\mathrm{B}^{+}$or safe breastfeeding). Other authors had even reported in a study conducted in West Africa in 2007 that more than half of the mothers had chosen breastfeeding despite the fact that milk substitutes are put at their disposal free of charge [18]. The issue of artificial feeding in the African context remains a dilemma for many nonbreastfeeding women; they are exposed to the risk of being rejected or stigmatized as shown by Oladokun et al. in their study [19]. The high proportion of breastfed children in this study is contrary to the one found in the research work of Sangho et al. in Mali in 2013 in which 93.2\% were fed with milk substitutes. During their study, the use of milk substitutes was motivated by the fact that they are provided free of charge, and by appropriate advices given to the mothers of those children concerning the hygienic conditions to be complied with during their restoration [9]. The infants put on breast milk substitutes did not experience contamination in this study. 
However, $5.6 \%$ of exclusively breastfed infants were contaminated versus $15.4 \%$ of those in whom mixed breastfeeding was applied although this difference was not statistically significant $(p=0.119)$. Indeed, there is evidence that mixed feeding, compared to exclusive breastfeeding and feeding with milk substitutes, may be associated with increased risk of HIV transmission [20]. As far as exclusive breastfeeding is concerned in this study, breastfeeding patterns influenced children's serological status at 18 months $(p=0.001)$. Exclusive breastfeeding which is not secured by ARV multiplied by 9.5 the risk of vertical HIV transmission. The adoption of option B+ in Benin since June 2013 and its extension in 2014 to all PMTCT sites will certainly play an important role in the elimination of HIV infection transmission among children in Benin.

Concerning children's nutritional status in this study, it was noted that overall acute malnutrition was observed in proportions ranging from $17.5 \%$ to $26.6 \%$ between the 6 th and 18th months of life. These relatively high proportions of overall acute malnutrition among the children mentioned above are not surprising. They are not surprising since a study on the anthropometric profile of children aged 0 to 59 months hospitalized in the same unit in 2010, had found an overall acute malnutrition rate of $25.3 \%$ [21]. Hence, nutritional recovery should be implemented for the benefit of those children, particularly during the post-weaning period. Actually, it is what is done during the follow-up of those children by using local products as well as ready-to-use therapeutic foods/RUTF (Plumpy Nut R) and sometimes therapeutic milk (F75, F100).

As regards the effectiveness of clean and safe birth, it was noted that $23.8 \%$ of children who did not benefit from a clean and safe birth were contaminated versus $2.4 \%$ of those who benefitted from that strategy during birth with a significant difference $(p<0.001)$. The risk of vertical HIV transmission is 12.4 times higher in children who did not benefit from clean and safe birth compared to their counterparts in whom clean and safe birth was performed.

The provision of maternal and childcare with ARV may also influence children's serological status at 18 months. In fact, we noted that the risk of vertical HIV transmission was 34.1 times higher in children from mother-child pairs who did not receive an ARV therapy compared to their counterparts who were administered that therapy $(p<0.001)$. This result confirms the efficacy of antiretroviral therapies in the elimination of motherto-child HIV transmission.

At the end of this study, a multivariate analysis points out that clean and safe birth and Antiretroviral prophylaxis in children at birth were the two predictive factors for risk of child contamination $(p=0.001)$. For a child who did not benefit from clean and safe birth, the risk of being contaminated is multiplied by 5.83 compared to the one who benefitted from it. In the same vein, as regards a child who did not receive antiretroviral prophylaxis at birth, the risk of being infected is multiplied by 15.3 compared to the one who received it.

\section{Outcome of followed-up children}

The results of this study point out that among 610 children who benefitted from serology at 18 months of age, $5.6 \%$ proved to be HIV-positive, including $41.2 \%$ of them who had previously a positive PCR 1 and $11.8 \%$ previously negative at PCR 1 . These results suggest that $2.3 \%(14 / 610)$ of children followed-up until 18 months of life were infected either during pregnancy or during birth and that $0.6 \%(4 / 610)$ of children got infected during the breastfeeding period. PCR1 remains a method for early diagnosis of HIV in exposed children. It enables a quick initiation of treatment that may delay clinical signs and reduce HIV-induced mortality [22]. The overall PMTCT failure rate estimated at $5.6 \%$ in this study is higher than the $3.6 \%$ rate reported by Ouédraogo et al. in a study conducted from January 1, 2012 to December 31, 2013 and focused on 238 HIV-positive pregnant women and their children in Burkina Faso [15]. This rate is higher than the $4.8 \%$ reported by Anoje et al. in a study carried out in the south of Nigeria between November 2007 and July 2009 and focused on 702 children born to HIV-positive mothers [23]. Much lower transmission rates ranging from $1.3 \%$ to $1.2 \%$ were reported respectively by Warszawski et al. [24] in the French perinatal survey in 2008 and by Wang et al. [25] in a prospective study conducted in eight regions of China in 2011. Agossou et al. [26] had reported in 2010 in the same hospital unit a failure rate for PMTCT estimated at 5.5\% (3/54) which is similar to the one found out in this study. This $5.6 \%$ transmission rate is identical to the one reported by Lawson-Evi et al. [27] in Togo in 2010 i.e. 5.6\% and less elevated than the one reported by Gbogbo [13] in Cotonou in 2011 i.e. 6.1\%. Other studies conducted in Africa and in the United States of America have highlighted transmission rates more elevated than ours. Moreover, Horwood et al. [28] in South Africa and Ngwej et al. [29] in the Democratic Republic of Congo, Del Blanco et al. [30] in Texas, reported rates respectively estimated at 7.1\%, $12.7 \%$ and $6 \%$ concerning vertical HIV transmission after 18 months of follow-up.

Concerning the children lost to follow-up in this study, more than one-third of them (36.5\%) were lost to follow-up. In the same hospital unit, since 2010 and in 2013, Agossou et al. [26] reported respective rates of lost to follow-up of $43.2 \%$ and $44.5 \%$. These results suggest an improvement in the follow-up of children born to HIV-positive mothers through the implementation of strategies aimed at active search for cases. In Togo, Lawson-Evi et al. [27] reported a drop-out rate of $52.2 \%$. In contrast, lower rates of lost to follow-up had been reported by two authors, namely Sangho et al. [9] in Mali, Azoumah et al. [7] in Togo i.e. respectively $18 \%$ and $8.7 \%$.

Among the 1234 children included in this study, 51 cases of death were registered i.e. a mortality rate of $4.1 \%$. This mortality rate is above the one reported by Gbogbo [13] in Cotonou in 2010 and estimated at $2.0 \%$. However, it is lower than the one reported by Sangho et al. [9] in Mali i.e. 9.3\%.

\section{CONCLUSION}

This study points out that more than one out of twenty infants born to an HIV-infected mother and followed-up in the Pediatric unit of CHUD-B/A had been infected with HIV. This research 
work also suggests that approximately four infants out of ten were lost to follow-up. The main factors associated with HIV transmission were absence of practice of clean and safe childbirth as well as lack of antiretroviral prophylaxis in followed-up infants. In response to these results, there is an urgent need to strengthen mechanisms to achieve early screening and ARV administration for pregnant women, as well as clean and safe childbirth. A mechanism should also be put in place to reduce the number of lost to follow-up, ensure antiretroviral prophylaxis from birth of exposed children and antiretroviral therapy for mothers. Finally, investigation of maternal viral load during pregnancy and breastfeeding may help identify other factors that influence vertical HIV transmission.

\section{ETHICAL AND PROFESSIONAL CONSIDERATIONS}

The CHUD-Borgou/Alibori administrative authorities approved the data collection before its implementation. Compliance with data confidentiality and anonymity was ensured.

\section{ACKNOWLEDGEMENT}

The authors thank the team of nurses and staff of the site for the care of children infected or exposed to HIV at CHUDBorgou/Alibori particulary, Mme SEIDOU-BOURAIMA Lahanatou.

They also thank the mothers and their children and the people who have worked in any way to follow-up these children.

\section{REFERENCES}

1. United Nations joint programme on HIV/AIDS (UNAIDS). Analysis of the epidemiological situation and epidemics response targeting key populations: Challenges and perspectives in the context of international commitments for universal access to HIV prevention and management services. Annual Report. 2015.

2. World Health Organization (WHO). Fact sheets: Global HIV and AIDS statistics. WHO. Aide-mémoire No.360.

3. Lala MM, Merchant RH. Merchant vertical transmission of HIVan update. Indian J Pediatr. 2010;77(11): 1270-1276.

4. Ciaranello AL, Perez F, Keatinge J, Parc JE, Engelsmann B, Maruva M, et al. What will it take to eliminate pediatric HIV? Reaching WHO target rates of mother-to-child hiv transmission in Zimbabwe: A model-based analysis. PLoS Med. 2012;9(1): e1001156.

5. Blanche S, Tricoire J. HIV infection in children, North- South aspects. Arch Pediatr Juin. 2009; 16(6): 652.

6. Ministry of health of Benin/national aids control program. Standards and procedures for the prevention of mother-to-child transmission of HIV in Benin. 4th edition, Cotonou. 2012; p: 105.

7. Azoumah KD, Lawson-Houkporti AA, Djadou KE, Tsolenyanu E, Lawson-Evi K, Améwuamé ANE, et al. Evaluation of prevention of mother-to-child HIV/AIDS transmission in the hospital of Bè in Lomé. JPP. 2011;24: 1-7.

8. Adédémy JD, Noudamadjo A, Agossou J, Alabi M, Adoukonou T, Adeothy-koumakpai S, et al. Anthropometric profile of children aged 1 to 59 months in 2010 in the pediatric unit of the Borgou
Regional Hospital in Parakou. Annales de l'Université de Parakou, Série: Sciences de la Santé. 2011; pp: 99-125.

9. Sangho H, Keita AS, Keïta HD, Sylla M, Dia A, Tayeb MM, et al. Follow-up of infants born to HIV-positive mothers in Mali. Revue de Santé Publique. 2013; 5:655

10. Tchiakpe E, Hounto-Ogouyemi A, Ndiaye HD, Diouara AAM, Aissi AK, Keke RK, et al. Use of capillary blood samples into blotting paper in early diagnosis of HIV 1 infection among children born to infected mothers within the framework of the prevention of mother-to-child transmission in Benin. Bull Soc Pathol Exot. 2016;109: 155-159.

11. Mnyani CN, Simango A, Murphy J, Chersich M, McIntyr JA. Patient factors to target for elimination of mother-to-child transmission of HIV. Global Health. 2014;10: 36.

12. Chibwesha CJ, Giganti MJ, Putta N, Chintu N, MulindwaJ, Dorton BJ, et al. Optimal time on HAART for prevention of mother-to-child transmission of HIV. J Acquir Immune Defic Syndr. 2011;58(2): 224-228.

13. Gbogbo TAH. Evaluation of health care provision for HIVexposed children in the pediatric unit of the National University Teaching Hospital/CHNU-HKM of Cotonou from June 2002 to December 2010, Thesis submitted for Ph.D. in Medicine, Faculty of Health Sciences. Cotonou. 2011; №1603, p: 120.

14. Yugbaré SOO, Zagré N, Koueta F, Dao L, Kam L, Ouattara Yé D, et al. Efficacy of prevention of mother-to-child transmission of human immunodeficiency virus through the world health organization 2010 guidelines at the saint camille medical center of ouagadougou (Burkina Faso). PAMJ. 2015;22: 303.

15. Ahoua L, Ayikoru H, Gnauck K, Odaru G, Odar E, OndoaOnama C, et al. Evaluation of 5-year program to prevent motherto-child transmission of HIV infection in northern Uganda, Jour Trop Ped. 2010;56: 43-52.

16. Soubeiga ST, Compaore R, Djigma F, Zagre N, Assengone E, Traore L, et al. Evaluation of antiretroviral therapy in HIV 1positive pregnant women on mother-to-child transmission of infection: A case study in saint camille medical center of ouagadougou/Burkina Faso. PAMJ. 2015;20: 399.

17. Foudaa GG, Jaegera FH, Amosa JD, Hoa C, Kunza EL, Anastia K, et al. Is an innate broad-spectrum, HIV-1-neutralizing protein in breast milk. PNAS. 2013;110(45): 18220-18225.

18. Tonwe-Gold B, Ekouevi DK, Viho I, Amani-Bosse C, Toure S, Coffie PA, et al. Antiretroviral treatment and prevention of peripartum and postnatal HIV transmission in west Africa: Evaluation of a two-tiered approach. PLoS Med. 2007;4(8): 257.

19. Oladokun RE, Brown BJ, Osinusi K. Infant feeding pattern of HIV-positive women in a prevention of mother-to-child transmission (PTMCT) programme. AIDS care. 2010;22 (9): 1108-14.

20. Noubiap JJN, Bongoe A, Demanou AS. Mother-to-child transmission of HIV: Findings from an early infant diagnosis program in bertoua, Eastern Cameroon. PAMJ. 2013;15: 65.

21. Adédémy JD, Agossou J, Noudamadjo A. State of mother-to-child transmission of HIV in pre- and immediate post-partum by PCR in Parakou. Book of Abstracts of the 5th Congress of the Gabonese Society of Pediatrics. Libreville, December 8-10, 2010.

22. Goetghebuer T, Haelterman E, Le Chenadec J, Dollfus C, Gibb D, Judd A, et al. Effect of early antiretroviral therapy on the risk of AIDS/death in HIV-infected infants. Aids. 2009; 23(5): 597-604.

23. Anoje C, Aiyenigba B, Suzuki C, Badru T, Akpoigbe K, Odo M, et al. Reducing mother-to-child transmission of HIV: Findings from an early infant diagnosis program in the south-south region of Nigeria. BMC Public Health. 2012;12:184. 
24. Warszawski J, Tubiana R, Le Chenadec J, Teglas JP, Faye A, Dolfus $\mathrm{C}$, et al. Mother-to-child HIV transmission despite antiretroviral therapy in the ANRS French Perinatal Cohort. AIDS. 2008;22(2): 289-299.

25. Wang Q, Wang L, Fang L, Wang A, Jin X, Wang F, et al. Timely antiretroviral prophylaxis during pregnancy effectively reduces HIV mother-to-child transmission in eight counties in China: A prospective study during 2004-2011. Scientific Reports. 6: 34526.

26. Agossou J, Adédémy JD, Salifou K, Noudamadjo A, d'AlmeidaHounnou M, Daho YJ, et al. Outcome at 18 months of children born to HIV-infected mothers in a hospital setting in the Northern-Benin. Rev. Maghr Pédiatr. 2010;20(6): 291-5.

27. Lawson-Evi K, Mouhari-Toure A, Tchama R, Akakpo SA, Atakouma DY, Beauvais L, et al. Outcome of children born to HIV-positive mothers followed up within the framework of the prevention of mother-to-child transmission in Togo: A case study of 1042 infants. Bulletin Soc Patho Exot. 103: 259-63.

28. Horwood C, Vermaak K, Butler L, Haskins L, Phakathia S, Rollins N, et al. Elimination of pediatric HIV in KwaZulu-Natal, South Africa: Large-scale assessment of interventions for the prevention of mother-to-child transmission. Bull World Health Organ. 2012;90:168-75.

29. Ngwej DT, Mukuku O, Mudekueza R, Karaj E, Odimba EB, Luboya ON, et al. Study of risk factors for mother-to-child transmission of HIV in the "Option A" strategy in Lubumbashi, Democratic Republic of Congo. PAMJ. 2015;15: 65.

30. Del-Bianco G, Bell CS, Benjamins LJ, Pérez N, Rodriguez G, Murphy JR, et al. Persistently high perinatal transmission of HIV: Assessment of risk factors. Pediatr Infect Dis J. 2014; 33(6): e151e157. 